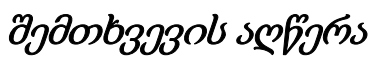

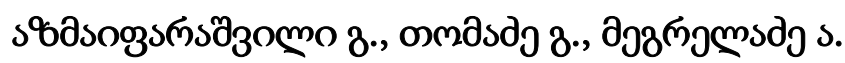

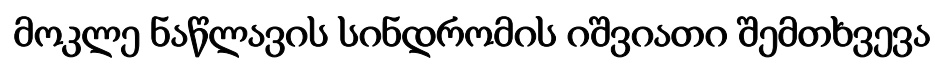

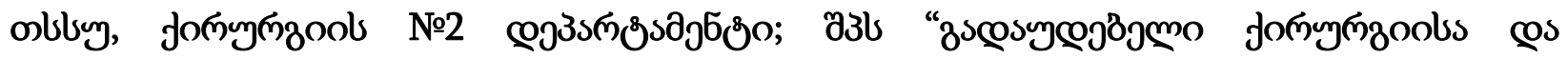

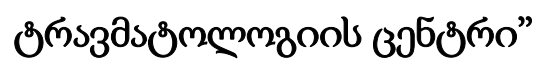

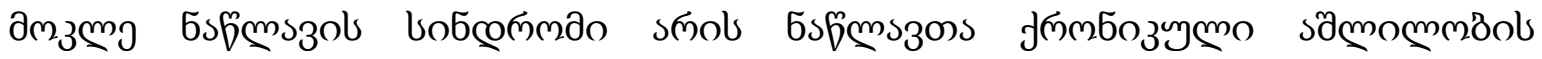

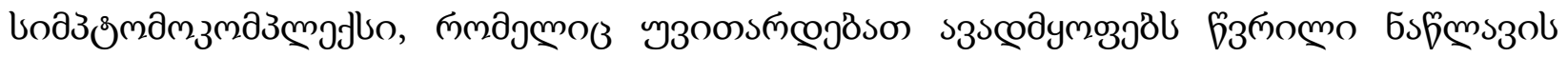

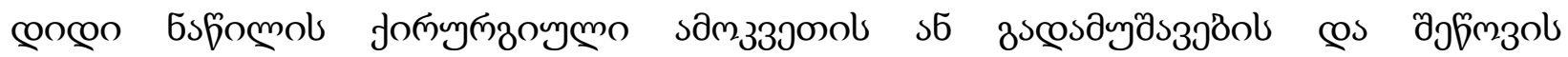

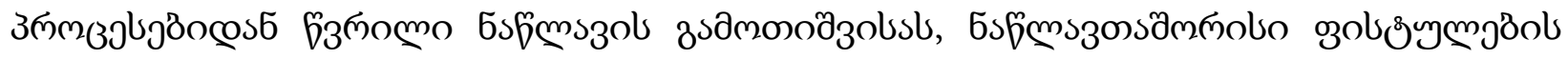

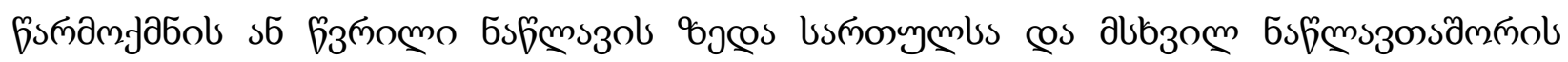

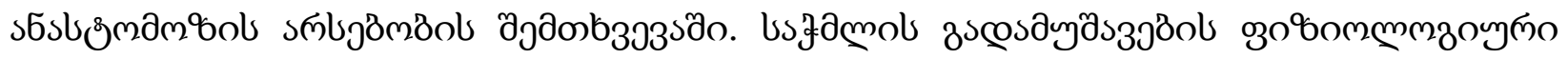

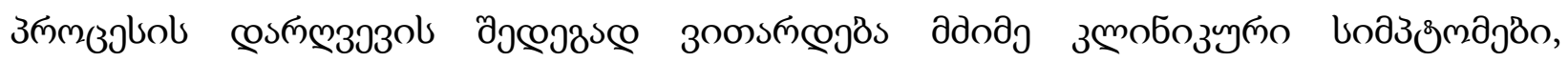

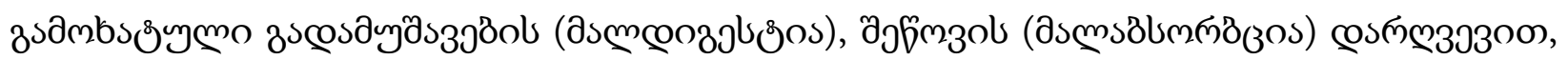

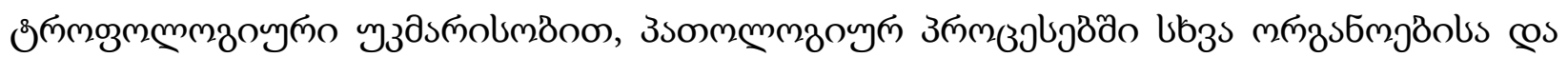

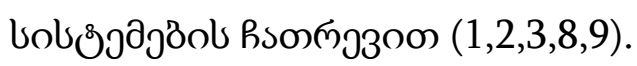

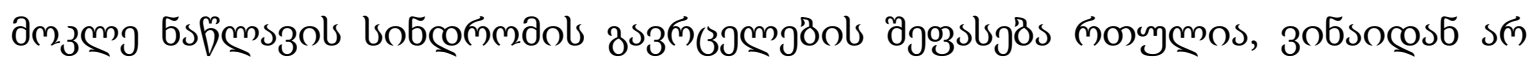

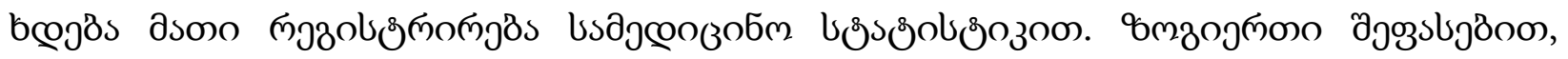

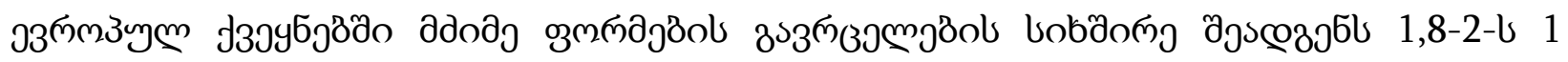
домомб s@sдоsб\% $(2,3,4)$.

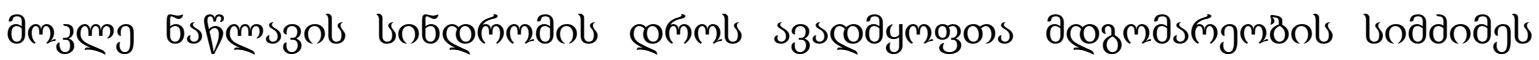

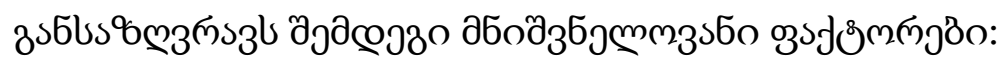

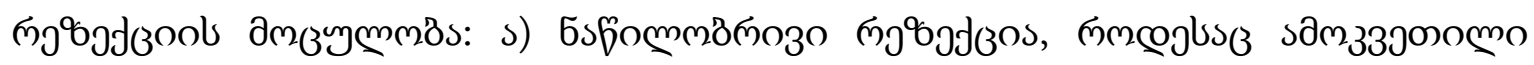

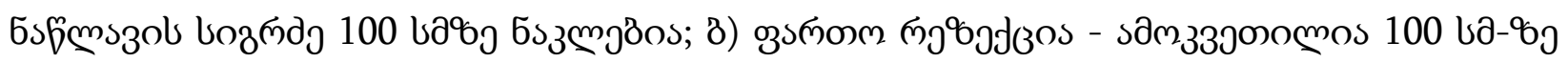

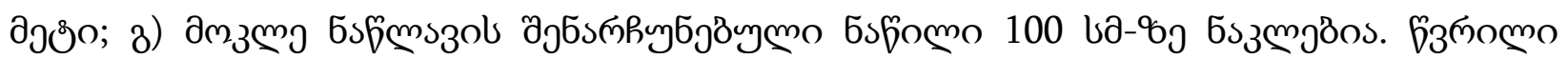

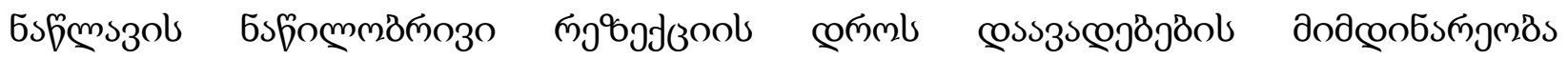

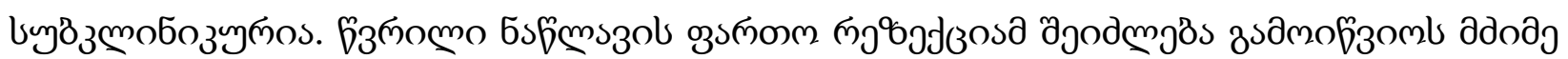

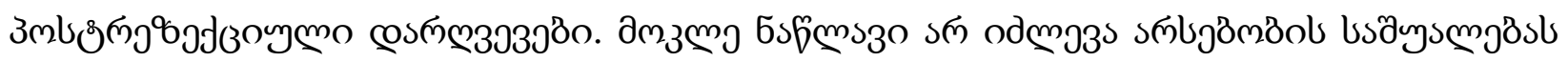

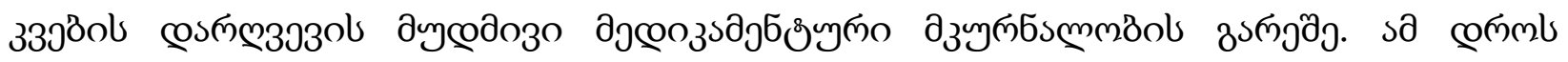

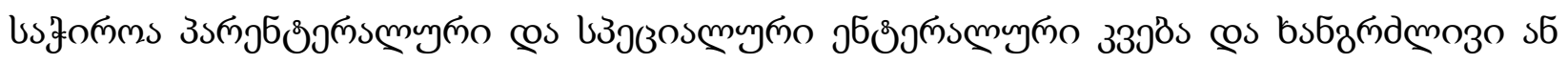

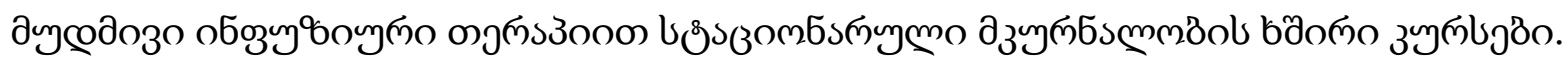

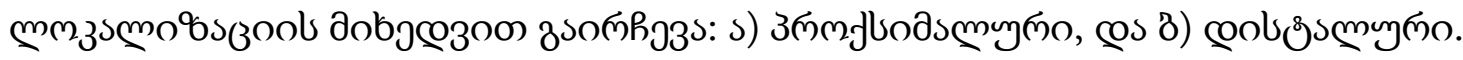

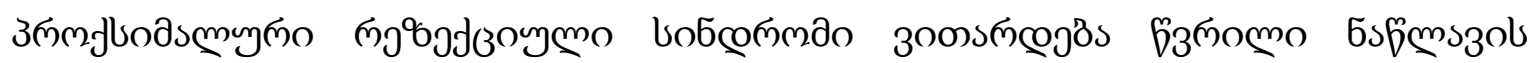

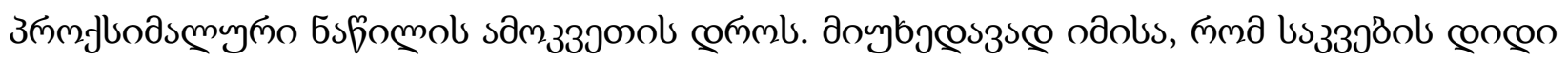




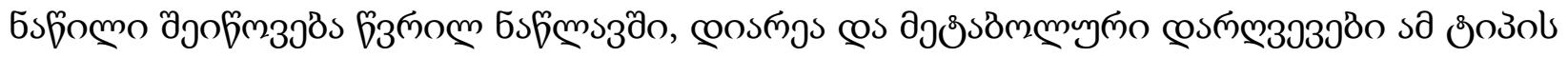

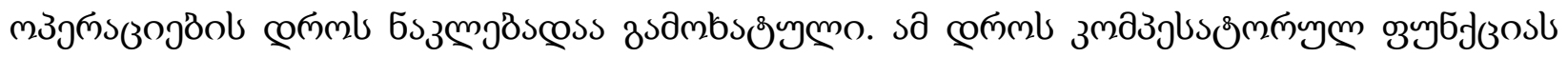

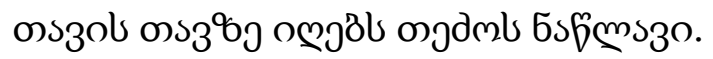

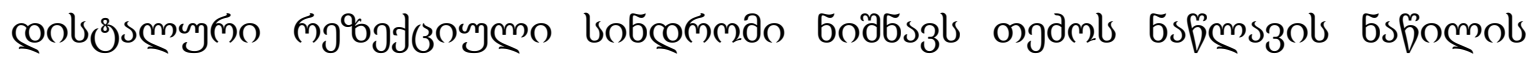

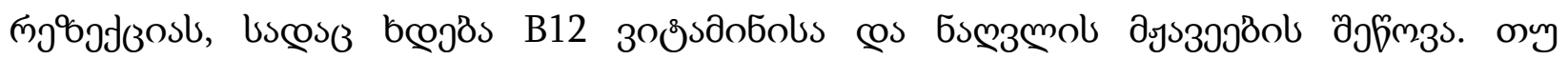

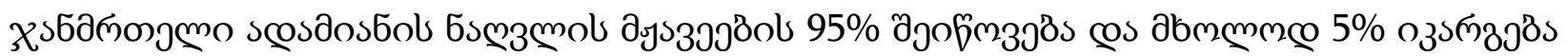

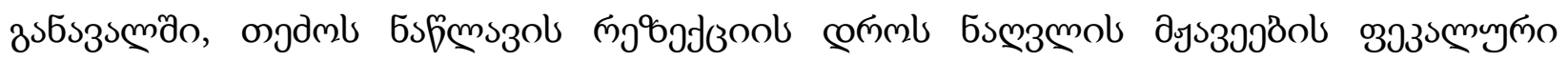

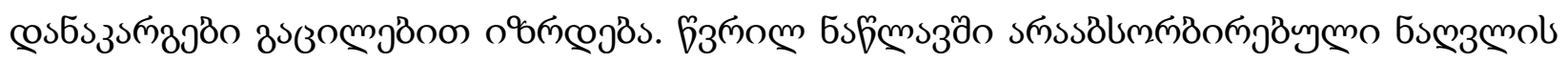

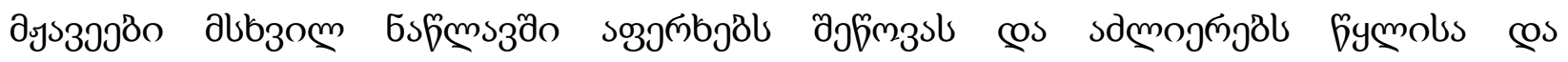

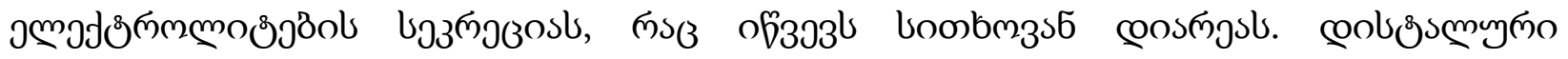

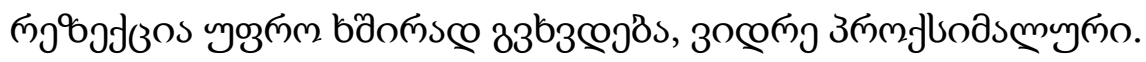

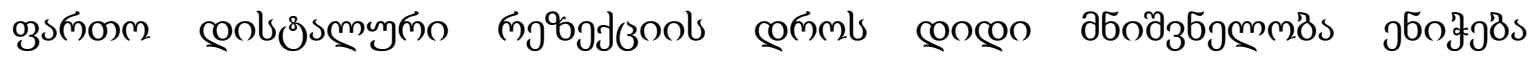

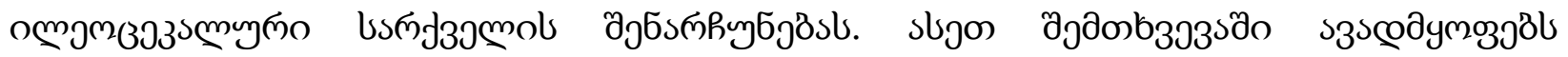
дбодзблммз

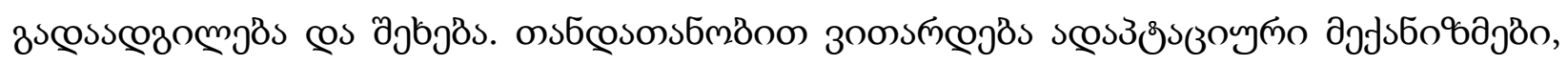

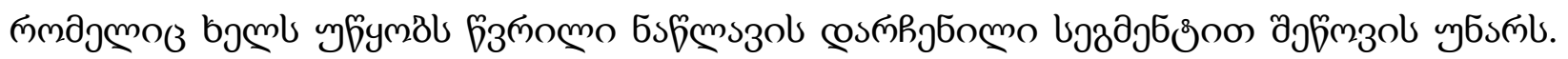

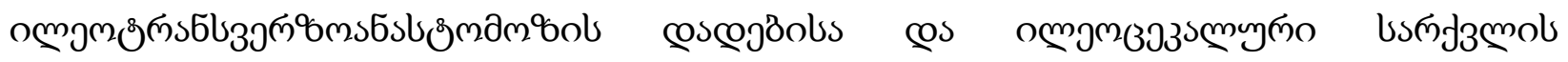

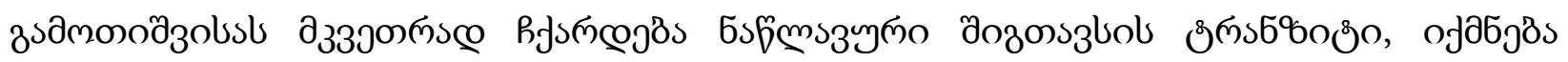

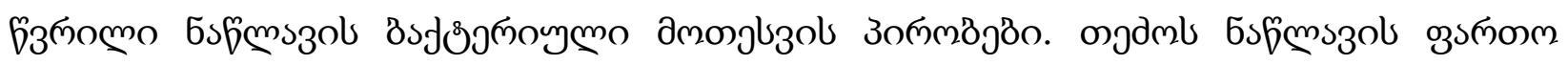

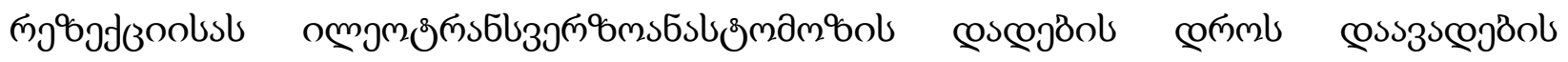

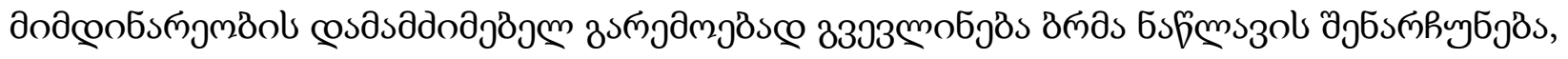

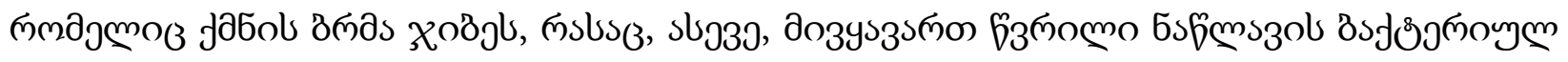

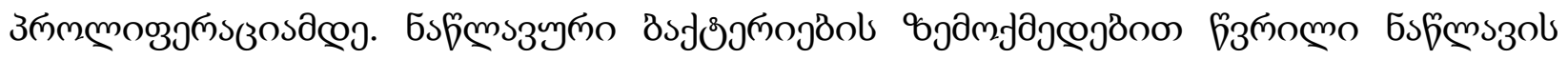

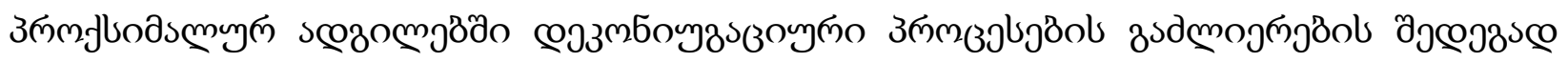

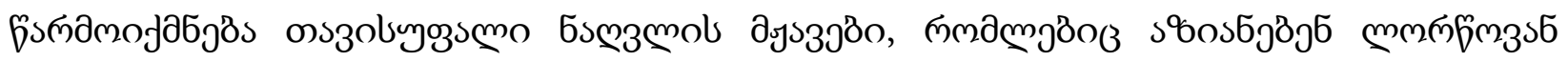

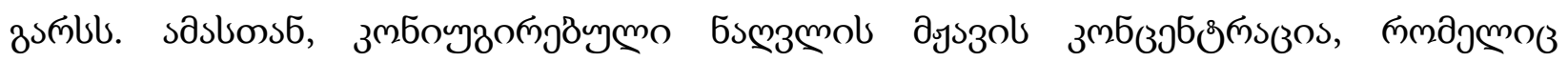

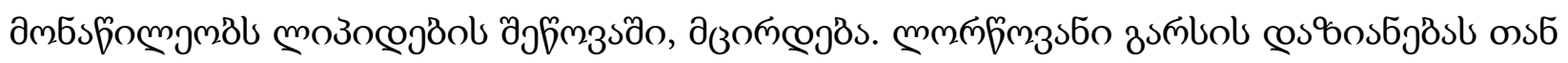

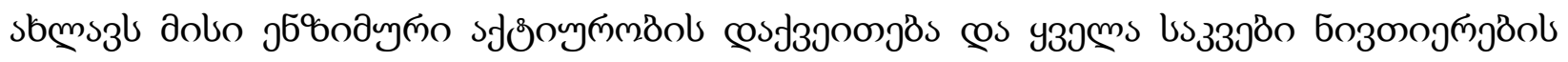

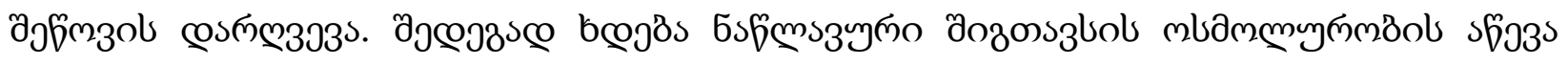

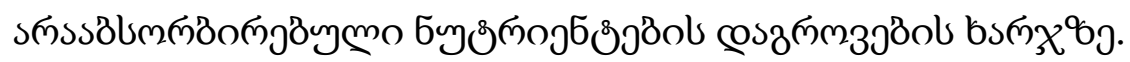

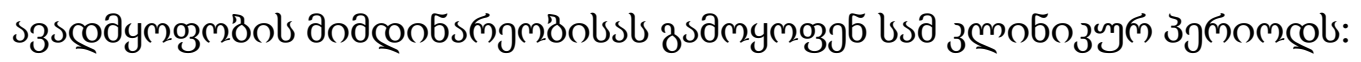

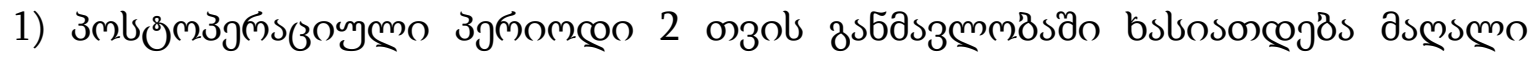

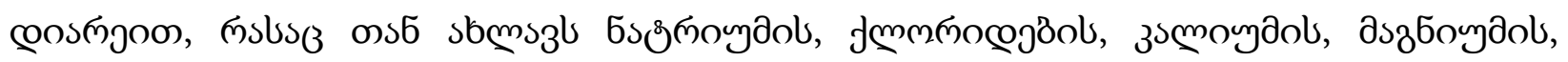

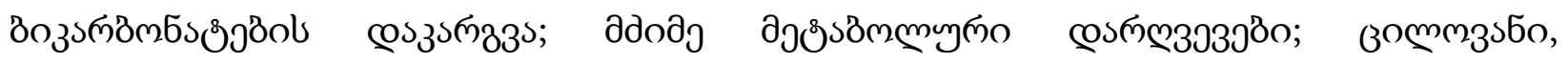

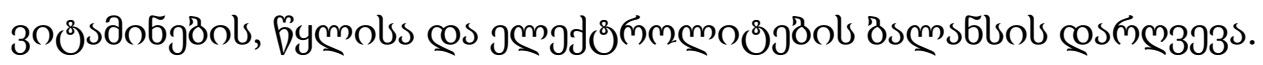




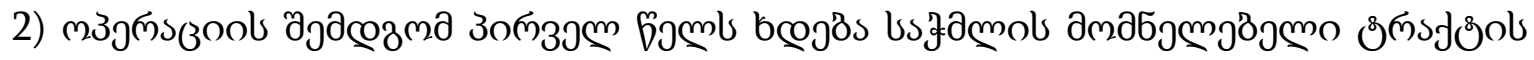

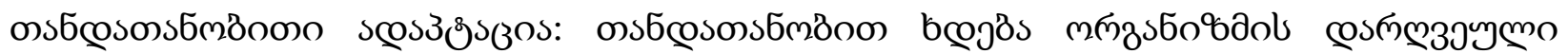

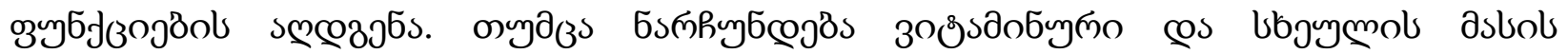

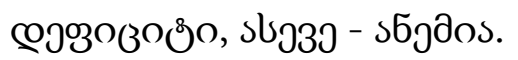

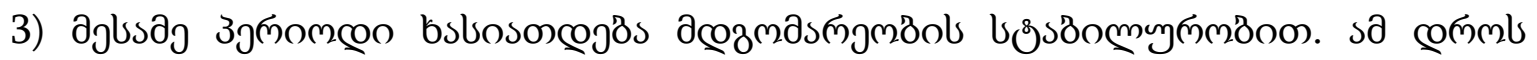

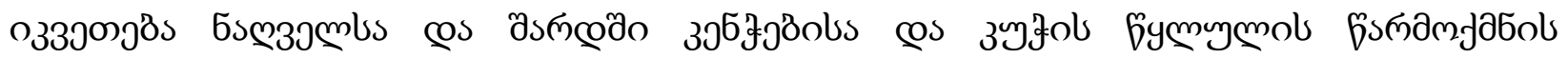

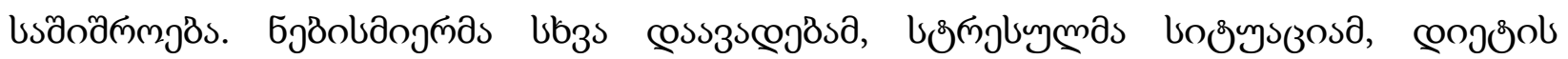

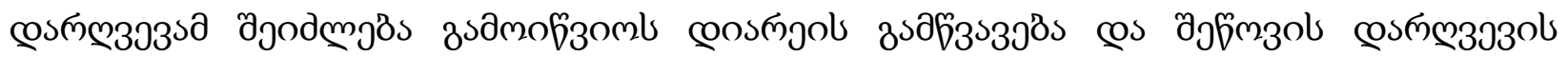
иобемпмдо.

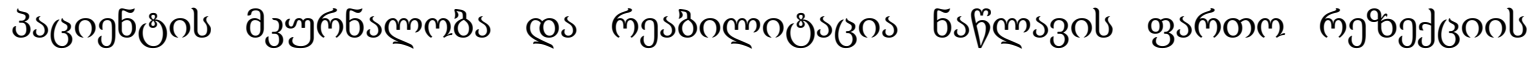

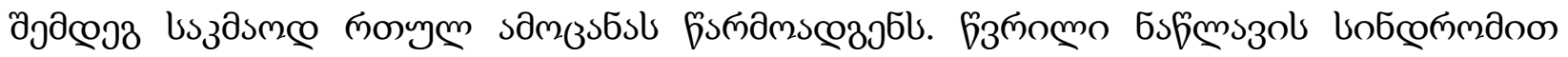

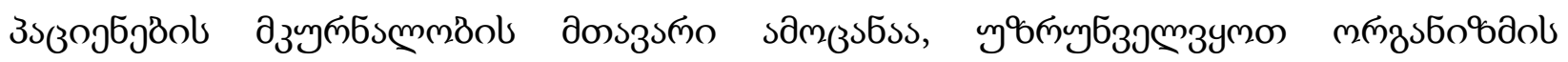

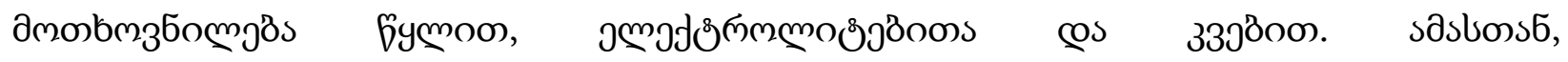

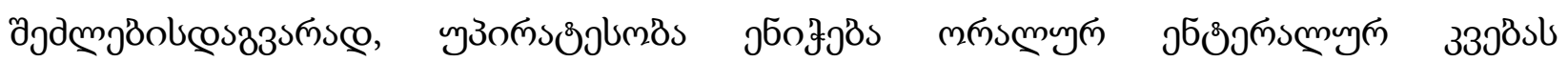

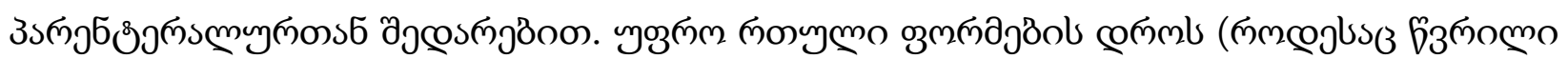

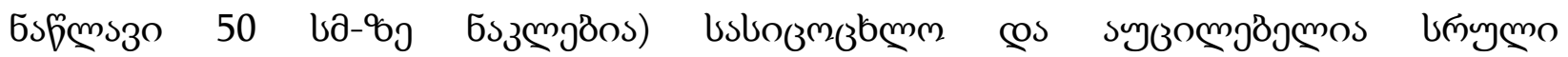

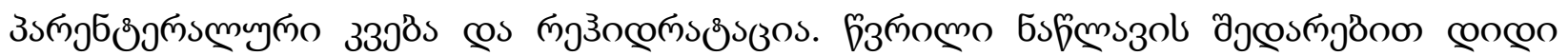

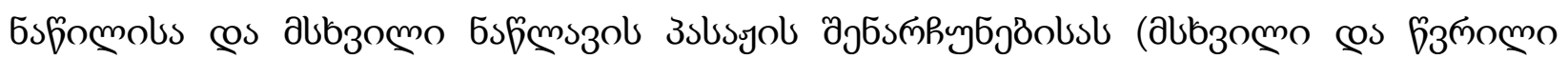

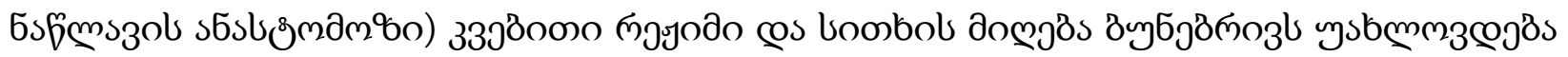
$(1,4,5,6,7)$.

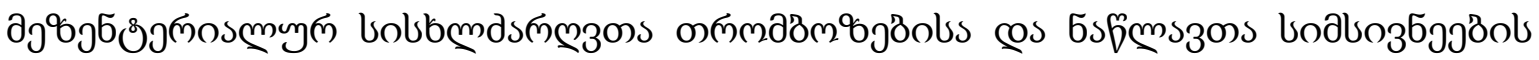

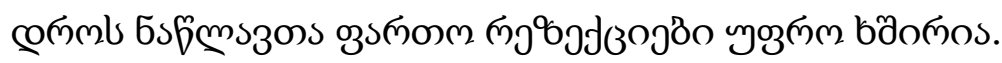

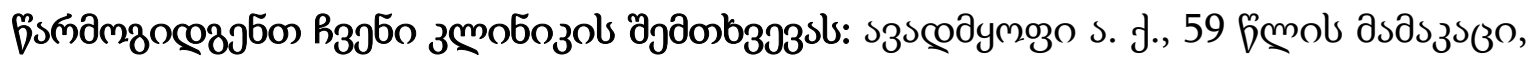

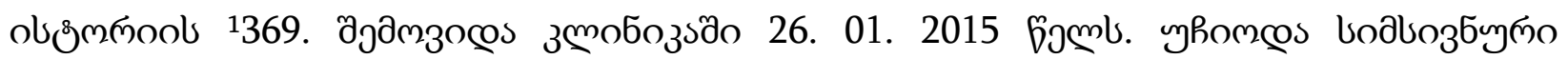

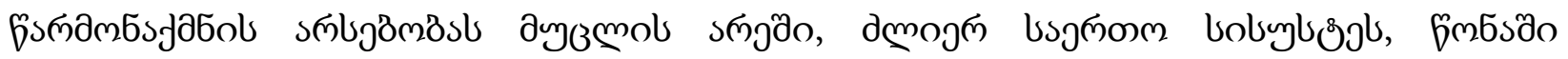

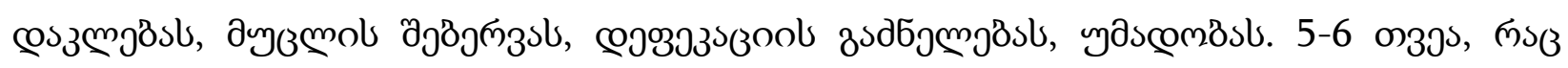

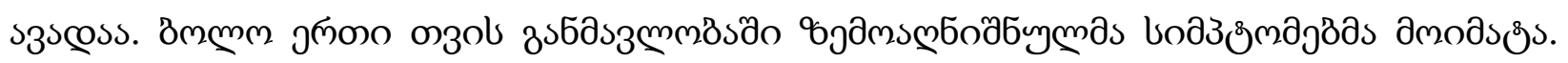

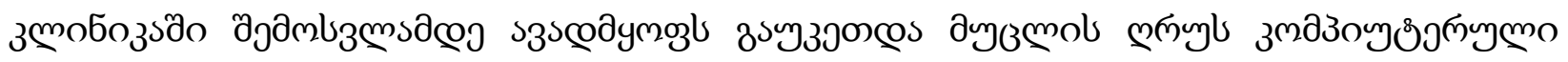

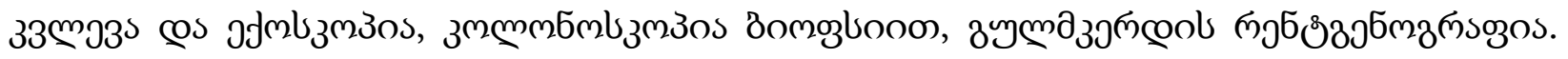

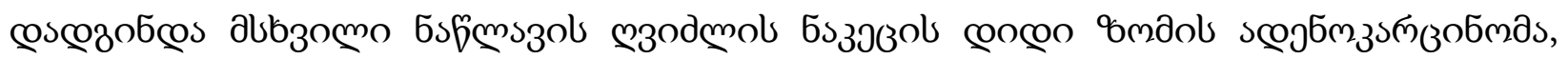

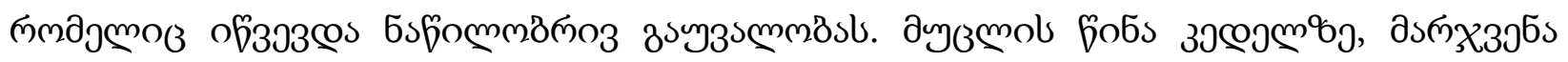

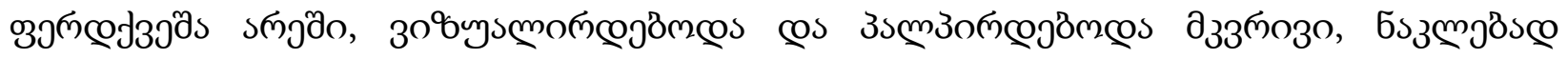

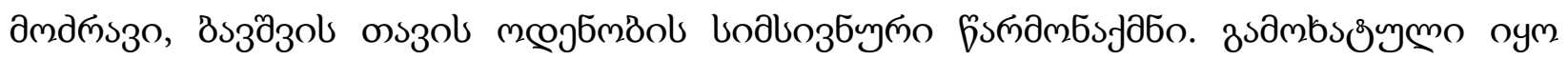

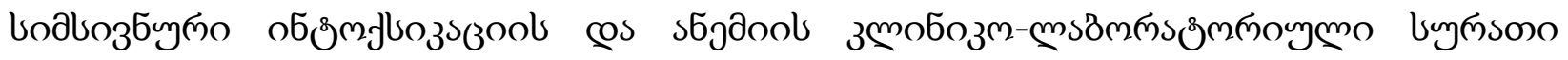

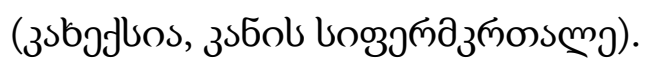




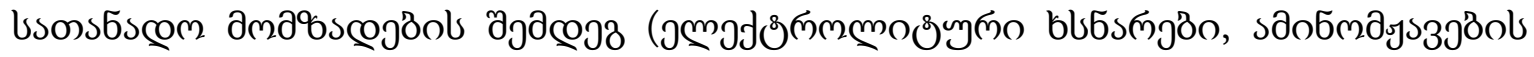

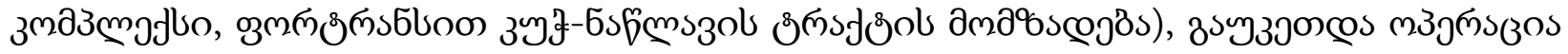

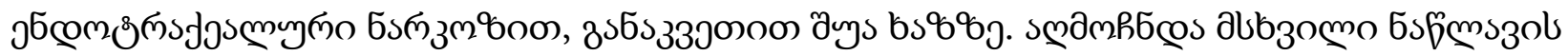

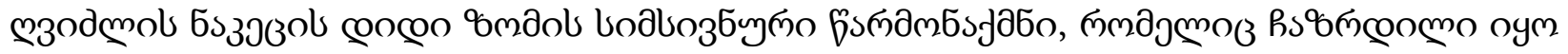

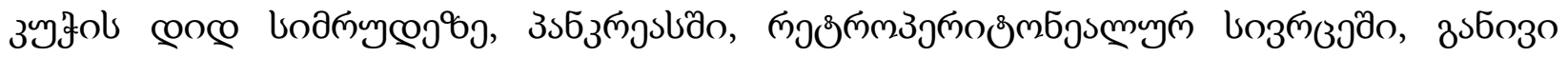

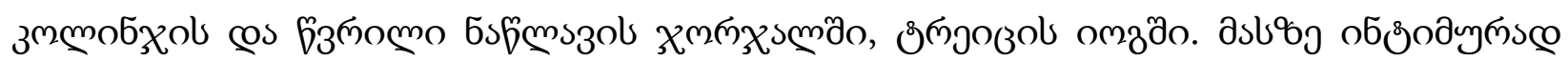

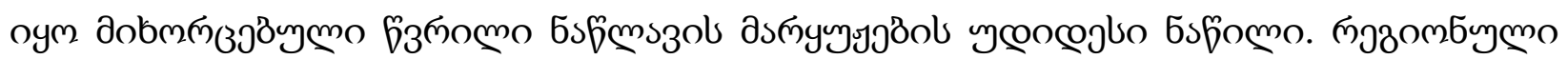

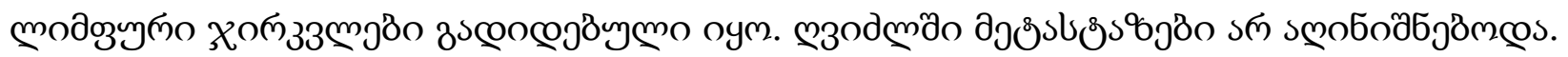

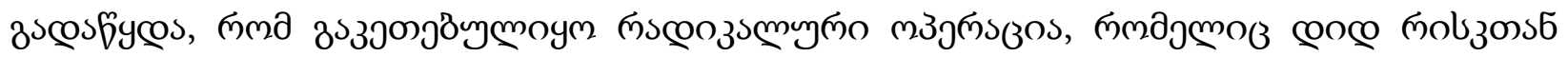

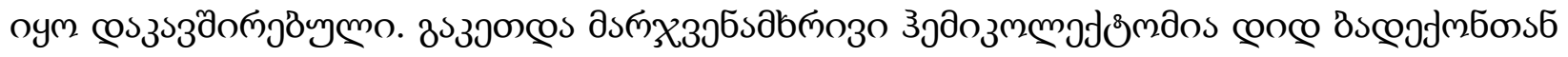

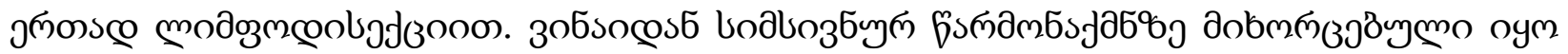

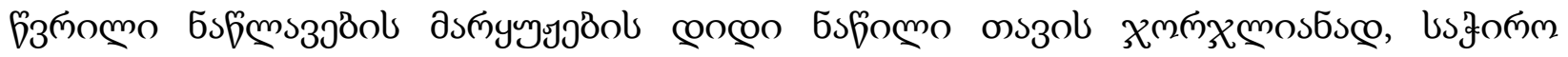

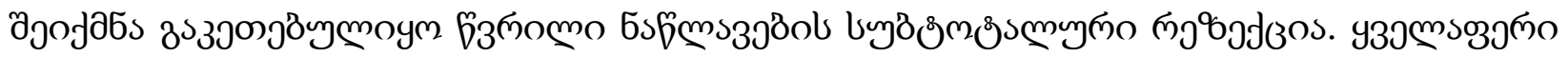

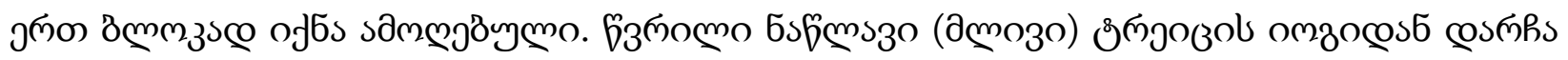

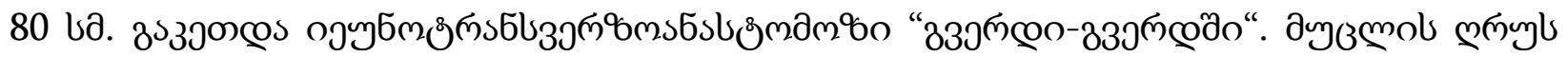

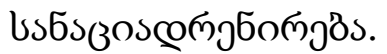

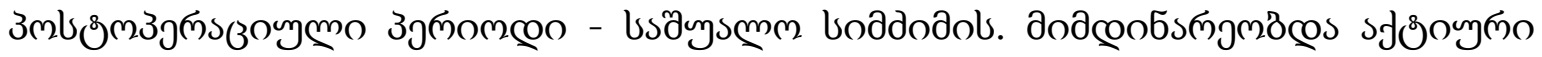

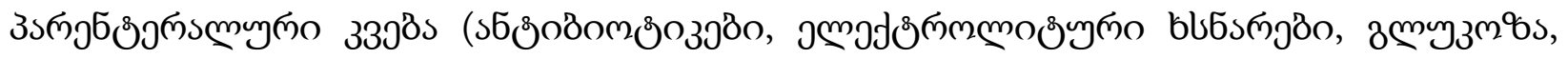

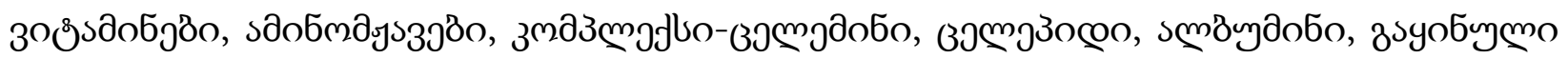

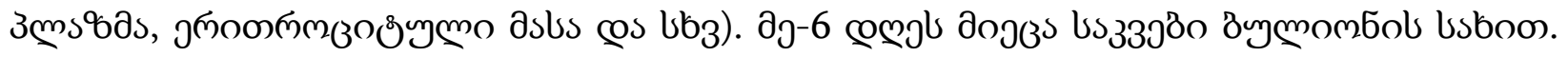

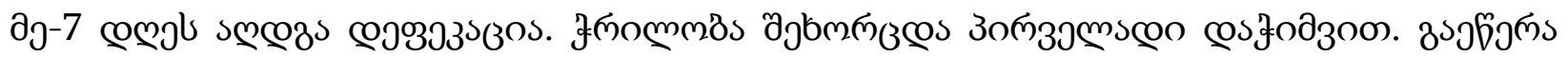

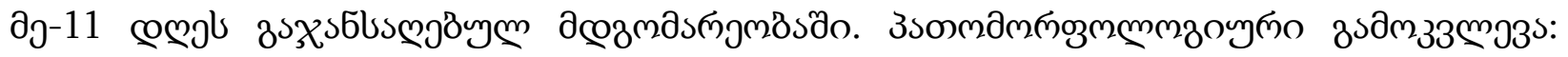

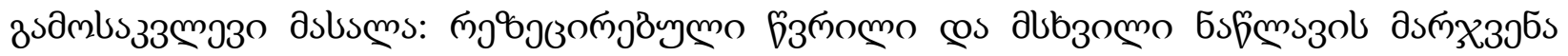

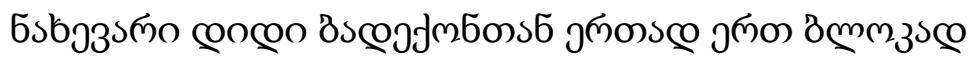

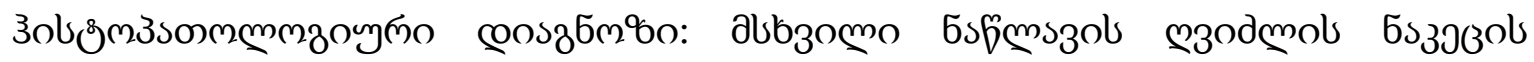

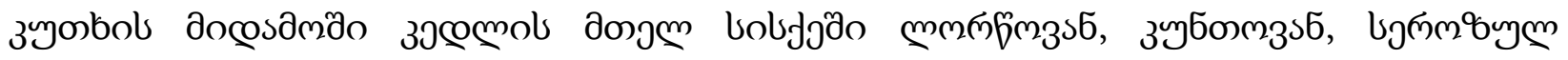

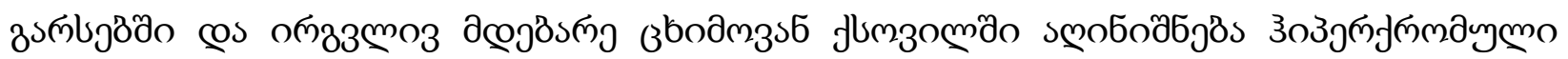

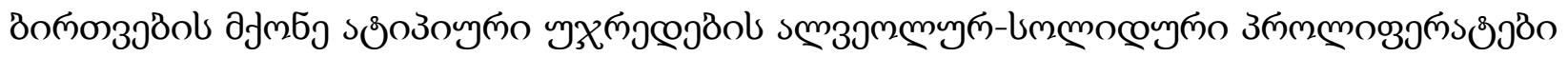

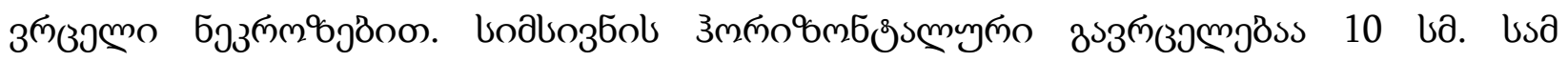

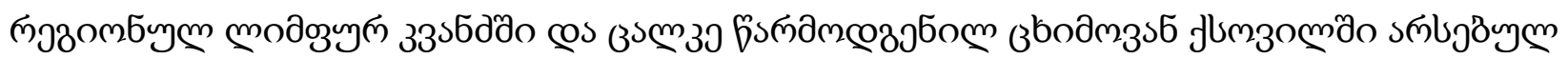

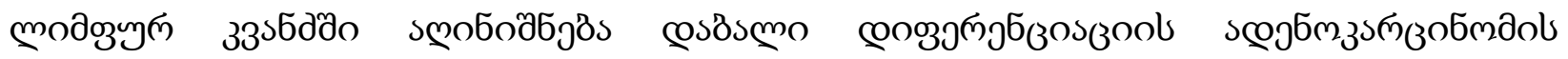

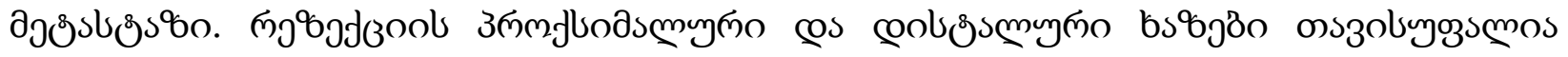

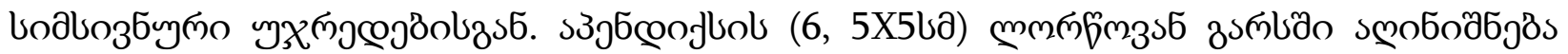

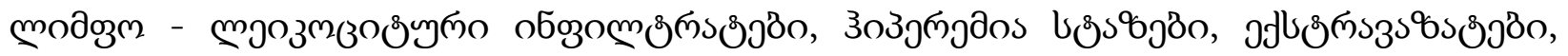

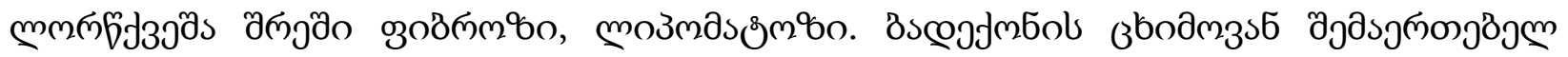




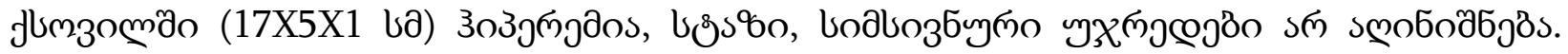

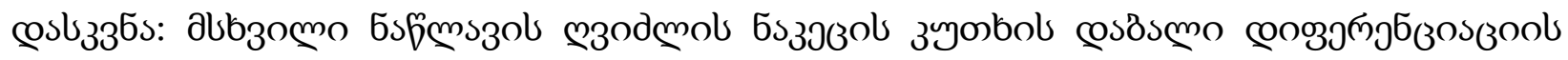

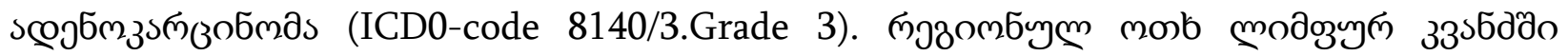

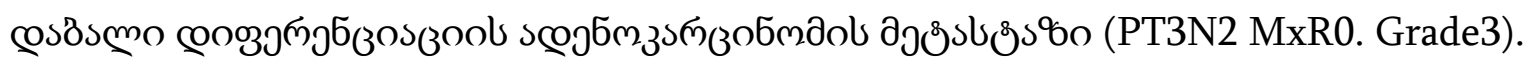

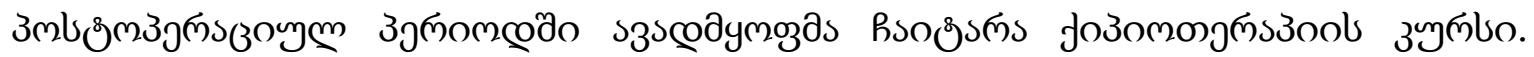

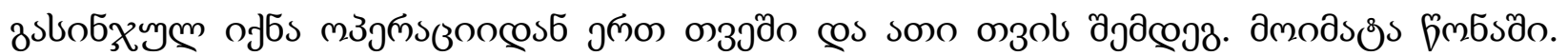

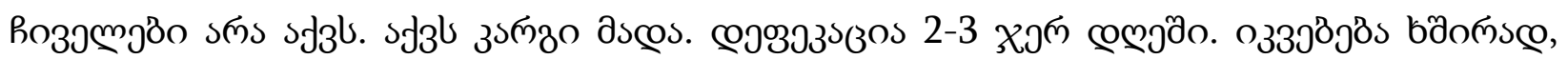

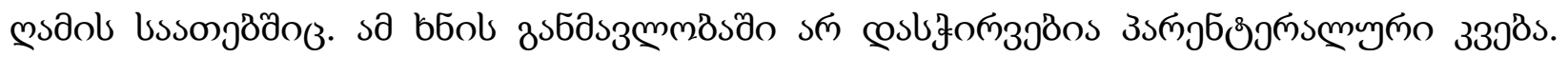
sзпд

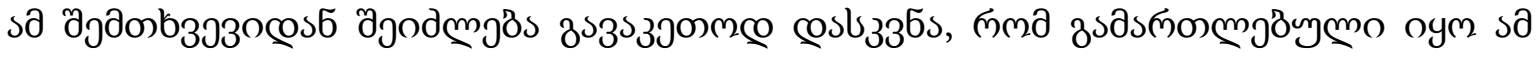

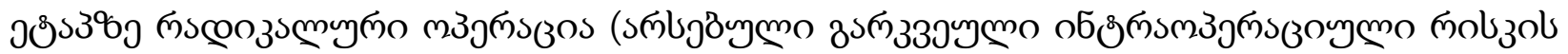

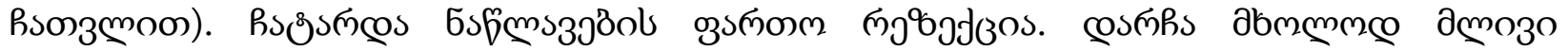

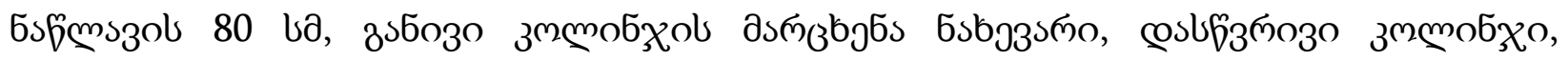

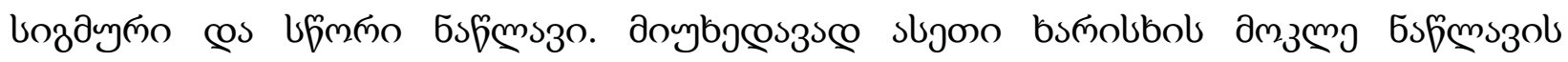

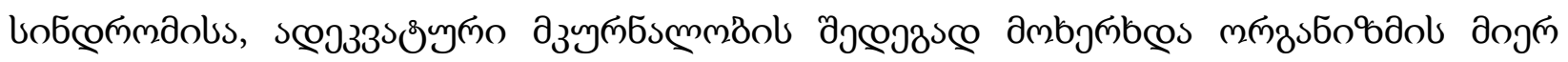

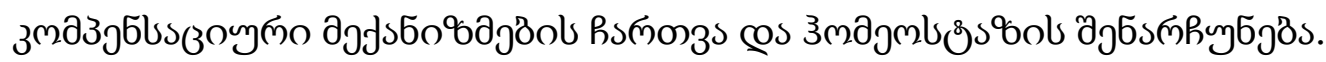

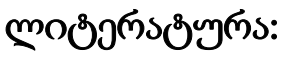

1. Баранская Е. К., Шульпекова Ю. О. Принципы ведения пациентов с синдромом короткого кишечника// Русский медицинский журнал : независимое издание для практикующих врачей. 2010. - Том 18, N 13. - С. 789-794.

2. Крумс Л.М., Сабельникова Е.А. Синдром короткой тонкой кишки: актуальные вопросы патогенеза, клиники и лечения / / Consilium medicum. 2002. № 2. С. 27-29.

3. Соломенцева Т.А. Синдром короткой кишки: тактика врача-гастроэнтеролога / / Острые и неотложные состояния в практике врача. - 2009. № 5. - С. 50-55.

4. Богомолов Б. П. Редкие клинические синдромы, протекающие с диареей. 1997. — № 11. — С. 16-18.

5. Sherwood, Lauralee (2006). Fundamentals of physiology: a human perspective (Third ed.). Florence, KY: Cengage Learning. p. 768.

6. Solomon et al. (2002) Biology Sixth Edition, Brooks-Cole/Thomson Learning

7. Townsend et al. (2004) Sabiston Textbook of Surgery, Elsevier

8. Thomson A, Drozdowski L, Iordache C, Thomson B, Vermeire S, Clandinin M, Wild G (2003). "Small bowel review: Normal physiology, part 1.”. Dig Dis Sci 48 (8): 1546-64. 
9. Gura KM, Duggan CP, Collier SB, et al. (2006). "Reversal of parenteral nutritionassociated liver disease in two infants with short bowel syndrome using parenteral fish oil: implications for future management”. Pediatrics 118 (1): e197-201

Azmaiparashvili G., Tomadze G., Megreladze A.

\section{RARE CASE OF SHORT BOWEL SYNDROME}

\section{TSMU, SURGERY DEPARTMENT \#2; CENTER OF EMERGENCY SURGERYAND TRAUMATOLOGY, LTD}

Short bowel syndrome is characterized by malabsorption following extensive resection of the small bowel. It may occur after resection of more than $50 \%$ and is certain after resection of more than $70 \%$ of the small intestine, or if less than $100 \mathrm{~cm}$ of small bowel remains.

Successful postoperative management of short bowel syndrome has been discussed. Patient was operated because of cancer of hepatic flexure of large bowel with invasion in stomach, pancreas, retroperitoneal space, mesentery of small bowel. Right sided colectomy and excessive resection of small bowel with limphodissection was performed and only $80 \mathrm{~cm}$ of small bowel was left together with the left part of the colon. Ileotransversoanastomosis was performed. After the adequate course of chemotherapy and partial parenteral nutrition patient's general condition became satisfactory. Patient started to gain weight. Adequate postoperative treatment determined postoperative period without surgical and nutritional complication. 